\title{
Comparing remote sensing and tabulated crop coefficients to assess irrigation water use
}

\author{
$\underline{\text { David Bretreger }}^{\mathrm{a}}{ }^{\circledR}$, Alexander Warner ${ }^{\mathrm{a}}$ and In-Young Yeo ${ }^{\mathrm{a}}(\mathbb{D}$ \\ ${ }^{a}$ School of Engineering, The University of Newcastle, Newcastle, NSW \\ Email: david.bretreger@uon.edu.au
}

\begin{abstract}
Agriculture accounts for approximately $72 \%$ of water use in Australia. This high volume of water use over many years has led to water sharing plans being implemented in regions of high agricultural activity, such as the Murray Darling Basin. Theoretically, the implementation of water sharing plans provides a sustainable solution for sharing this resource between irrigators, communities and the environment. Although, currently there are minimal options to choose from to monitor water use without visiting sites, which can be time consuming and cost prohibitive. There is a need to monitor the water used by the various stakeholders within the system, to monitor, and regulate, for its long-term success and sustainability.
\end{abstract}

This paper compares a previously developed approach for monitoring irrigation water use via remote sensing of crop coefficients $\left(K_{c}\right)$, and gridded climate data with a repurposed irrigation scheduling approach, recommended by State Governments in Australia using tabulated $K_{c}$ and rain gauges (using Food and Agriculture Organisation Paper 56 (FAO56) methodology). The tabulated values have been locally derived, which is often important in accounting for environmental factors which may not occur elsewhere in the world. The remote sensing relationships used were derived in North America over a range of crops, which may introduce errors. Although the remote sensing methodology possesses many benefits as it does not require knowledge of seasonal growth and soil characteristics. The comparisons were performed over an almond orchard in the Northern Adelaide Plains and a vineyard located in the McLaren Vale wine region, both in South Australia.

This study found that the remote sensing approach provided better results for the almond plantation, which is thought to be due to the management of almonds agreeing with hydrological assumptions made during the methodology derivation. Conversely, the vineyard returned better results using the localised tabulated $K_{c}$; thought to be due to an induced water stress, a common farming practice used to produce quality fruit and wine products. It is evident that the remote sensing relationships are unable to monitor these management strategies. The sparse canopy cover of wine grape vines may also be contributing to the limitation of the remote sensing methodology.

The remote sensing method has definite advantages compared to using tabulated values as it shows an actual $K_{c}$, as opposed to a theoretical $K_{c}$, removing the possibility of disease and other non-typical conditions going unnoticed in the tabulated method. The remote sensing method removes the need for modellers to obtain data on planting dates, soil texture/hydraulic characteristics and detailed knowledge of crop type. A tabulated method is likely more difficult from a technical perspective to scale up to a catchment/basin scale extent that covers multiple crop/land use types. Overall, this paper demonstrates that the tabulated $K_{c}$ method can be used to monitor irrigation on farm scale sites. Although, despite its shortcomings, the use of the remote sensing method allows the simulation to be performed in remote areas where there is little to no in-situ measurements and shows greater ability and potential to be scaled to larger regions.

Keywords: Irrigation, remote sensing, water accounting, water management 


\section{INTRODUCTION}

Water is a limiting factor in ecosystem functioning across the majority of Australia, with agriculture accounting for approximately $72 \%$ of water extractions in Australia for the 2017-18 water year (BoM, 2019). This is of particular concern in regions of Australia, like the Murray Darling Basin which have high agricultural productivity, and where town drinking water, and correct ecosystem functioning relies on water from the basin (Hart, 2016). Water sharing plans aim to minimise over use of water, this is achieved by outlining sustainable levels of extraction for irrigators, among other controls. Enforcement of this water quota on the agriculture sector, will theoretically leave enough water for communities and the environment. Although, for this to be effective there needs to be a reliable method for monitoring water use in remote and regional areas. Regional areas are more susceptible to the risks of failed equipment, because of isolation, and many regional areas may be inconvenient for staff to access and perform proper monitoring for the water use in that area.

The tabulated $K_{c}$ values have been used for many years, predominately for irrigation scheduling following the methodology set out in Food and Agriculture Organisation Paper 56 (FAO56) (Allen et al., 1998). As irrigation water use is becoming an important issue in the Australian context, the repurposing of this technique to monitor past irrigation water use is an important avenue to consider.

A clear limitation of the tabulated values is they lack the ability to show variations from typical behaviour of crops, this neglects environmental factors like water stress, disease, pests, salinity or nutrient poor soils. Although Pereira et al. (2015) states that remote sensing $K_{c}$ relationships have somewhat addressed this limitation. They also benefit by not needing to know planting dates, as the airborne sensors observe instantaneous conditions. Through these differences, a tabulated $K_{c}$ and a remote sensing derived alternative can have large differences in final values (Rocha et al., 2012).

Literature from sources around the world state that a localised $K_{c}$ is of vast importance for accurate irrigation scheduling (Allen et al., 1998; D'Urso, 2010; WA DPIRD, 2016). These localised values can account for environmental variables such as drought, unique soil types or management techniques. Localised tabulated values are available for Australia (Natural Resources SA, 2015), although crop specific remote sensing equivalent are hard to come by and have not performed well against general North American relationships in previous studies (Bretreger et al., 2019).

This paper presents two methods for accounting for irrigation water use, using a tabulated $K_{c}$ and a remote sensing $K_{c}$, applied in different methodologies and compares the output to observed irrigation data. It aims to answer the question, despite the benefits and drawbacks of each method how do localised tabulated $K_{c}$ values perform against generic remote sensing relationships.

\section{METHODS}

\subsection{Tabulated Crop Coefficient Method}

The tabulated methodology is based on irrigation scheduling advice published by various Australian State Government agriculture departments (Vic Agriculture, 2012; WA DPIRD, 2016), which are predominately based on the methods set out in the FAO56 report (Allen et al., 1998). The method relies on monitoring the soil water deficit by performing a basic water balance using the precipitation and actual evapotranspiration. The actual evapotranspiration is found by:

$A E T=E T_{0} \times K_{c}$

where $A E T$ is the actual evapotranspiration ( $\mathrm{mm}), E T_{0}$ is the reference evapotranspiration (mm) and $K_{c}$ is the crop coefficient. The $K_{c}$ in this case is taken from pre-defined monthly values for each crop as published by Natural Resources SA (2015). The effective rainfall is calculated from the rainfall records using the rules set out by Vic Agriculture (2012); the effective rainfall is the rainfall minus $5 \mathrm{~mm}$ for each daily total in spring, summer and autumn. In winter, all rainfall is assumed effective. The soil water deficit is calculated via the equation:

$S W D_{i}=S W D_{i-1}+P_{e}+\operatorname{Irr}-A E T$

where $S W D$ is the soil water deficit at time $i(\mathrm{~mm}), P_{e}$ is the effective rainfall $(\mathrm{mm}), \operatorname{Irr}$ is the irrigation $(\mathrm{mm})$ and $A E T$ is the actual evapotranspiration $(\mathrm{mm})$. The irrigation is triggered from when the soil water deficit reaches a refill point, based on soil hydrologic characteristics, which prevents the crop from experiencing water stress. The deficit levels allowed is based on the readily available water (RAW) and the rooting depth, which are multiplied together to get an applied irrigation depth. The estimates can differ over a single field site and 
hence both the deep and shallow extents of the irrigation depths are applied as a comparison. Once the irrigation is applied, the soil water deficit is reset to 0 . The applied irrigation is summed monthly and over each growing season for annual values, months outside the typical growing season are excluded from simulation. This is defined by the published $K_{c}$ values by Natural Resources SA (2015).

\subsection{Remote Sensing Method}

The remote sensing methodology follows previously published work (Bretreger et al., 2019). This method calculates the irrigation depth on a monthly scale. To do this it makes assumptions about a natural water balance with anthropogenic influences which results in negligible runoff and deep drainage, while also assuming soil moisture remains constant, which is generally performed as a management strategy to avoid crop water stress. This results in the following equation for irrigation depth:

$\operatorname{Irr}=A E T-P$

where $\operatorname{Irr}$ is the irrigation depth $(\mathrm{mm}), A E T$ is the actual evapotranspiration $(\mathrm{mm})$ and $P$ is the precipitation (mm). The AET is calculated via the same method as the tabulated method in equation (1), although the $K_{c}$ is a result from the remote sensing relationships.

There are two remote sensing relationships tested in this paper. The first equation tested is from the IrriSat Irrigation Scheduling Application (https://irrisat-cloud.appspot.com/); the relationship as defined by Hornbuckle et al. (2016) is:

$K_{c}=1.37 \times N D V I-0.086$

where NDVI is the normalized differential vegetation index. The resulting $K_{c}$ from equation (4) will be referred to as Irri from this point onwards. An alternative method derived by Kamble et al. (2013) which was also derived over a range of crop types is used as a comparison which is defined by:

$K_{c}=1.4571 \times N D V I-0.1725$

where NDVI is the normalized differential vegetation index. As in previous studies, a mulching factor is applied to these relationships when simulating the wine grapes field as there is evidence of plastic mulching (Pitt et al., 2015), there is no evidence of mulching on the almond field. This results in a $30 \%$ reduction in $K_{c}$ (Allen et al., 1998). There are published relationships specifically for certain crops, although previous testing has shown these return results with less accuracy than the relationships presented here (Bretreger et al., 2019).

To compare the results from each of the methods, a root mean square error (RMSE) was calculated for monthly and summed annual values. Additionally, the ratio of estimated to actual irrigation is calculated for annual values, with a value of 1 meaning the simulation is averaging the correct value and over 1 showing overestimation and values under 1 showing underestimation.

\section{STUDY AREA AND DATA}

\subsection{Study Sites and Irrigation Observations}

The study regions for this paper are over two sites. These sites were selected due to being monoculture cropping fields and having a temporal resolution or irrigation observations to compare with published tabulated $K_{c}$ values. The fields are both located in South Australia which have previously been used by the South Australian Research and Development Institute (SARDI) for saline irrigation research (Pitt et al., 2015); one is an almond plantation in the Northern Adelaide Plains with 3 years of data; the second field is a vineyard located in the McLaren Vale wine region with 4 years of data. Details of these fields are shown in Table 1 and Figure 1.

Table 1. Details and locations of study sites

\begin{tabular}{ccccc}
\hline Crop & Location & Length of Data & $\begin{array}{c}\text { Latitude, } \\
\text { Longitude }\end{array}$ & Area (ha) \\
\hline \multirow{2}{*}{ Almond } & Northern Adelaide & July 2013- & $-34.628^{\circ}$, & \multirow{2}{*}{3.5} \\
& Plains, SA & June 2016 & $138.683^{\circ}$ & \\
\multirow{2}{*}{ Wine Grape } & $\begin{array}{c}\text { McLaren Vale wine } \\
\text { region, SA }\end{array}$ & $\begin{array}{c}\text { July 2011 - } \\
\text { June 2015 }\end{array}$ & $\begin{array}{c}-35.239^{\circ}, \\
138.523^{\circ}\end{array}$ & \multirow{2}{*}{28} \\
\hline
\end{tabular}




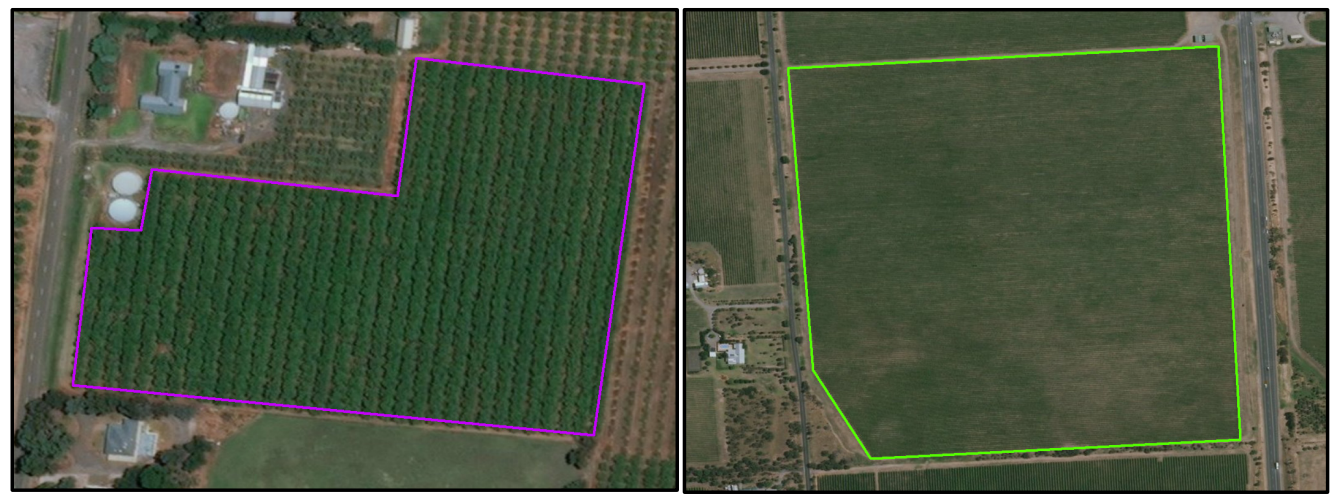

Figure 1. Aerial images of the almond (left) and wine grapes (right) fields used in this study

In the tabulated $K_{c}$ methodology, soil hydraulic characteristics are taken into account. These values are taken from Pitt et al. (2015), which specifies the almond field had a RAW of 20-30 mm with a rooting depth of $0.6 \mathrm{~m}$. The vineyard was reported with a RAW of between 35-44 mm and a rooting depth of 0.6-0.8 m. Multiplying these to find a maximum and minimum value, gave irrigation depths of $12-18 \mathrm{~mm}$ and $20-35 \mathrm{~mm}$ for the almond and wine grapes respectively. These values were used when calculating irrigation applications to fill soil water deficits. As a range was provided, the maximum and minimum values were both included in results as the shallow and deep irrigation depths.

\subsection{Crop Coefficients Sources}

Tabulated $K_{c}$ are published in numerous places, although the majority are divided into early, mid and late stages of growth; not monthly localised values. This makes it difficult to determine which values to use and when to use them. Rather than use ambiguous $K_{c}$ values, the tabulated method uses monthly localised $K_{c}$ values published by the South Australian Government. Natural Resources SA (2015), gives monthly values for a large number of crops that include the almond and wine grapes being compared in this paper.

The remote sensing data used to find the $K_{c}$ comprises of the red and near-infrared bands of the Landsat series of satellites. Landsat 5, 7 and 8 were used on the vineyard while only Landsat 7 and 8 were operating as almond irrigation data was collected. The 16 day revisit time of each satellite when combined provides an approximate weekly temporal resolution, which is averaged monthly. The satellite images were loaded from Digital Earth Australia (DEA) (Dhu et al., 2017). Digital Earth Australia provides the Landsat images with a $25 \mathrm{~m} \mathrm{x} 25 \mathrm{~m}$ resolution which have been through the built in correction process (Sixsmith et al., 2013) and have pixel quality masking for cloud and shadow interference.

\subsection{Meteorological Data}

The meteorological data used in this study consists of precipitation $(\mathrm{P})$ and reference evapotranspiration $\left(E T_{0}\right)$. Each of the methods have used different sources to obtain data that is likely to represent actions in an operational context. The $E T_{0}$ values are downloaded as both an American Society of Civil Engineers (ASCE) (tall) (Allen et al., 2000) and FAO56 (short) (Allen et al., 1998) variations. The tall and short $E T_{0}$ methods are applied to the almond and wine grapes respectively, due to the aerodynamic conductance of each crop being represented better by these products. Results showing this have been presented in previous publications (Bretreger et al., 2018; Bretreger et al., 2019).

The tabulated method has used point data available from the nearest available stations (not grid interpolations), downloaded from SILO (https://silo.longpaddock.qld.gov.au/). The data used for the remote sensing methodology is downloaded from the BoM Australia Water Landscape Balance website (http:/www.bom.gov.au/water/landscape), which supplies data from the Australian Water Resources Assessment Landscape model (AWRA). AWRA v6 provides the data for this paper (Frost et al., 2018), which is presented on a interpolated grid with a resolution of approximately $5 \mathrm{~km}$ by $5 \mathrm{~km}$.

\section{RESULTS AND DISCUSSION}

The time series results in Figure 2 show that the almond observation time series is between the remote sensing and tabulated simulations. The overestimation of the remote sensing may be due to the assumptions being made that runoff and deep drainage are negligible and hence any that do occur are effectively counted as an irrigation flux. Although this potential overestimation is minimal when compared the magnitude of underestimation 
resulting from the use of the tabulated methodology. The differences between the two remote sensing methods are extremely small showing almost no difference in the majority of months whereas the deep and shallow tabulated irrigation can show changes of up to $\sim 30-40 \mathrm{~mm}$ each month, showing the sensitivity of soil hydraulic characteristics when using this methodology.

Comparing the wine grapes time series shows that both the remote sensing and tabulated values are drastically over estimating the observed irrigation. Although the tabulated results are performing slightly better. The plant structure of wine grape vines may also make the remote sensing approach provide unreliable results as the NDVI is an observation of canopy cover which can be relatively bare compared to many crops. The differences in both the almond and wine grapes time series shown here, is evidence that the $K_{c}$ value used can cause large differences in the final irrigation estimation, as suggested by Rocha et al. (2012).
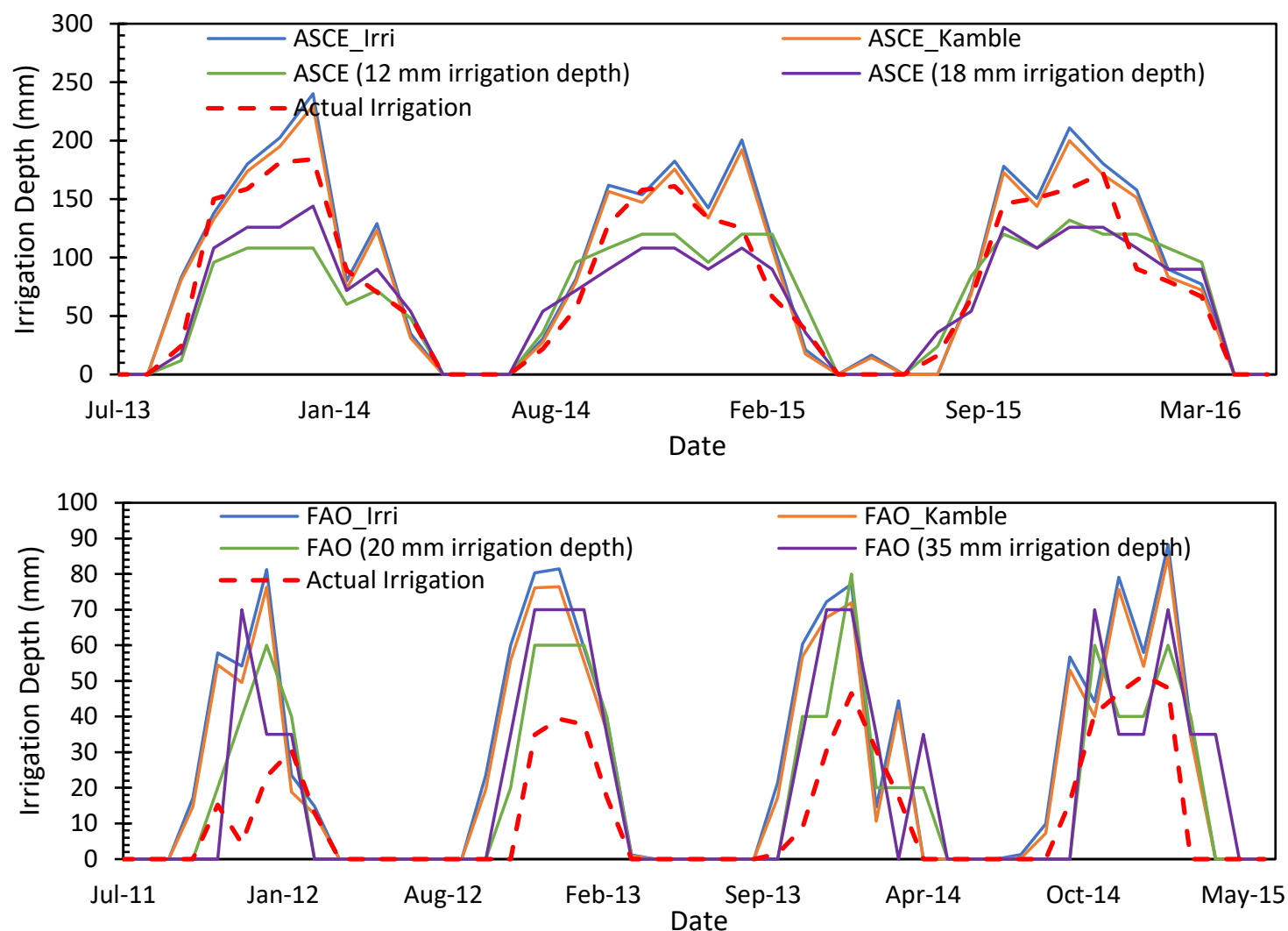

Figure 2. Various irrigation simulations compared with observed time series for almond (top) and wine grape (bottom)

From the ratios in Figure 3 and the values in Table 2, we can see that the remote sensing relationships seem to work better for the almond plantation while the wine grapes seem to be better simulated using the tabulated values. The almond field produces a best case simulation ratio of 1.14 for remote sensing while it is at 0.87 for the tabulated method. Although the standard deviation shows a large uncertainty when using the tabulated method here, giving more reliability to the remote sensing. When looking at the RMSE, the monthly simulations only alter slightly with best simulations only differing by $0.8 \mathrm{~mm}$, although the remote sensing returns the better result. The annual RMSE shows more evidence of the remote sensing performing better with approximately $10 \mathrm{~mm}$ between them. Although these results are similar, the remote sensing method requires less information to be able to perform the simulation, meaning it may be useful, particularly in rural areas without accurate soil characteristic measurements.

The results in Figure 3 and Table 2 for the wine grapes tells a different story. The remote sensing relationship is vastly overestimating the irrigation (ratios of 2.20 and 2.38) as was observed in previous studies (Bretreger et al., 2018; Bretreger et al., 2019), this is with a mulching factor in place to somewhat counteract this management strategy's effect on the water balance. Although the tabulated method's ratios are not performing as well as the almond simulations, it is still showing a great improvement over using remote sensing. The standard deviations of the remote sensing and tabulated methods are similar when simulating the wine grapes field. The RMSE of the wine grapes field using the tabulated shallow irrigation depth shows a substantially 
better irrigation simulation compared to other techniques. Although the remote sensing does take into account mulching, other management techniques, such as voluntarily induced water stress which are commonly applied to wine grapes (Chaves et al., 2007; Van Leeuwen et al., 2009) are not considered. The results here show that the use of localised tabulated values return better results for irrigation when crop specific management techniques are used. This creates the option for localised remote sensing relationships to be derived to account for some of the specific management techniques used which may improve the remote sensing results adjust the differences seen here.
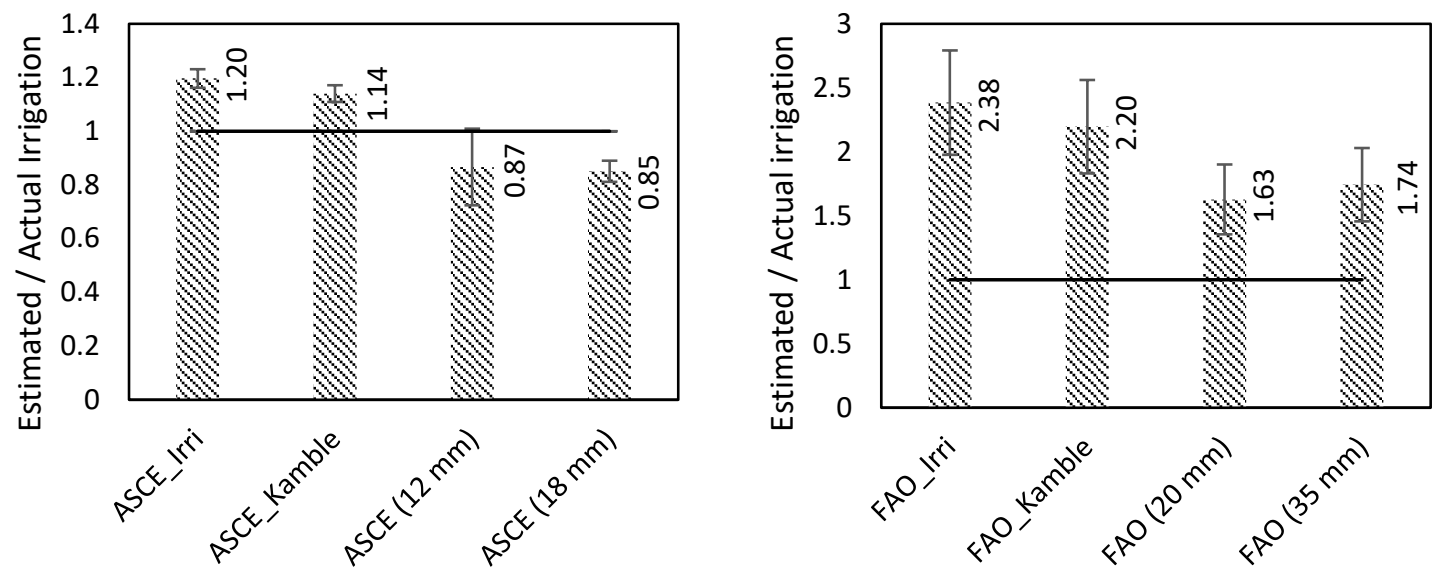

Figure 3. Ratio of estimated irrigation to observed irrigation for each method tested over the almond (left) and wine grapes (right). Error bars show \pm 1 standard deviation, with the black line showing where a ratio of 1 occurs. Values to the right of the columns show the ratio value.

Table 2. Root mean square error $(\mathrm{mm})$ of the various irrigation simulations. Results shown include remote sensing methods using the Irrisat (RS - Irri) and Kamble (RS - Kamble) equations and the tabulated results for shallow (Tab - Shallow) and deep (Tab - Deep) irrigation depths. The best results are shaded and in bold.

\begin{tabular}{cccccc}
\hline \multicolumn{2}{c}{ Crop } & RS - Irri & RS - Kamble & Tab - Shallow & Tab - Deep \\
\hline \multirow{2}{*}{ Almond } & Monthly & 29.47 & $\mathbf{2 6 . 0 5}$ & 31.91 & 26.87 \\
& Yearly & 182.21 & $\mathbf{1 3 0 . 8 3}$ & 179.49 & 141.16 \\
\hline \multirow{2}{*}{ Wine } & Monthly & 24.82 & 22.54 & $\mathbf{1 4 . 8 7}$ & 19.59 \\
Grapes & Yearly & 177.93 & 153.89 & $\mathbf{8 0 . 8 9}$ & 104.29 \\
\hline
\end{tabular}

\section{CONCLUSION}

This study aims to show potential differences and inform users of the changes that may be seen when choosing between using tabulated $K_{c}$ or using remote sensing derived alternatives. We found that when simulating irrigation water use over the almond plantation, the generic remote sensing methods provided similar if not better results compared to the localised tabulated values. It also had a much lower standard deviation, indicating a more precise output. The added benefit of the remote sensing observations is that they can be used with less knowledge of on the ground conditions and will somewhat account for unexpected changes in growth patterns. The tabulated $K_{c}$ method may improve with the creation of a range of localised values for each management scenario but with currently available data, the remote sensing relationships seem to provide a better option.

The wine grape field showed that in some instances the remote sensing was vastly over estimating the irrigation water use. This is predominately attributed to the specific management strategies associated with wine grapes. The localised tabulated values of $K_{c}$ provided much better results compared to remote sensing. This is thought to be caused by the $K_{c}$ values being locally derived and crop specific. This has likely allowed for specific management techniques and local conditions to be accounted for. For wine grapes, and other crops with unusual or specific management strategies, it is recommended that localised tabulated $K_{c}$ values be used.

In their current state, the remote sensing or tabulated methods could be used to assess irrigation water use with some accuracy as long as the potential issues are known and investigated in individual cases. The tabulated values method shows a limitation in its ability to be scaled to larger extents covering multiple crop/land use types while also requiring accurate soil hydraulic characteristics to be known. The potential work arising from this paper include the development of localised remote sensing relationships for the Australian setting which 
may improve simulations. These may take into account the various management strategies of specific crops, such as wine grapes, which was observed to cause errors in this paper.

\section{ACKNOWLEDGEMENTS}

The authors would like to acknowledge the South Australian Research and Development Institute (SARDI) for sharing the irrigation observation data for the sites used in this study. David Bretreger is supported by an Australian Government Research Training Program Scholarship.

\section{REFERENCES}

Allen, R.G., Pereira, L.S., Raes, D., Smith, M., 1998. Crop evapotranspiration - Guidelines for computing crop water requirements - FAO Irrigation and drainage paper 56. Food and Agriculture Organization, Land and Water, Rome, Italy.

Allen, R.G., Walter, I.A., Elliot, R.L., Howell, T.A., Itenfisu, D., Jensen, M.E., Snyder, R.I., 2000. ASCE Standardized Reference Evapotranspiration Equation, National Irrigation Symposium. Environmental and Water Resources Institute of the American Society of Civil Engineers, Phoenix, Arizona.

BoM, 2019. Water in Australia 2017-18. Bureau of Meteorology, Melbourne, Victoria, Australia.

Bretreger, D., Quijano, J., Awad, J., 2018. Monitoring Irrigation Volumes using Climate Data and Remote Sensing Observations, 38th Hydrology and Water Resources Symposium (HWRS 2018): Water and Communities. Engineers Australia, Melbourne, Australia, pp. 112-123.

Bretreger, D., Yeo, I.-Y., Quijano, J., Awad, J., Hancock, G., Willgoose, G., 2019. Monitoring irrigation water use over paddock scales using climate data and landsat observations. Agricultural Water Management 221, 175-191.

Chaves, M.M., Santos, T.P., Souza, C.R., Ortuño, M.F., Rodrigues, M.L., Lopes, C.M., Maroco, J.P., Pereira, J.S., 2007. Deficit irrigation in grapevine improves water-use efficiency while controlling vigour and production quality. Annals of Applied Biology 150, 237-252.

D'Urso, G., 2010. Current Status and Perspectives for the Estimation of Crop Water Requirements from Earth Observation. Italian Journal of Agronomy 5, 107-120.

Dhu, T., Dunn, B., Lewis, B., Lymburner, L., Mueller, N., Telfer, E., Lewis, A., McIntyre, A., Minchin, S., Phillips, C., 2017. Digital earth Australia - unlocking new value from earth observation data. Big Earth Data $1,64-74$.

Frost, A.J., Ramchurn, A., Smith, A., 2018. The Australian Landscape Water Balance model (AWRA-L v6). Bureau of Meteorology, Australia.

Hart, B.T., 2016. The Australian Murray-Darling Basin Plan: factors leading to its successful development. Ecohydrology \& Hydrobiology 16, 229-241.

Hornbuckle, J., Jamie, V., Carlos, B., Janelle, M., Robert, H., Robert, B., 2016. IrriSAT Technical Reference. Deakin University, CSIRO Land \& Water, NSW DPI, Australia.

Kamble, B., Kilic, A., Hubbard, K., 2013. Estimating Crop Coefficients Using Remote Sensing-Based Vegetation Index. Remote Sensing 5, 1588-1602.

Natural Resources SA, 2015. Crop Kc Values (FAO56). Natural Resources South East, Department of Environment and Water, Adelaide, South Australia.

Pereira, L.S., Allen, R.G., Smith, M., Raes, D., 2015. Crop evapotranspiration estimation with FAO56: Past and future. Agricultural Water Management 147, 4-20.

Pitt, T., Cox, J., Phogat, V., Fleming, N., Grant, C., 2015. Methods to increase the use of recycled wastewater in irrigation by overcoming the constraint of soil salinity. South Australian Research and Development Institute (SARDI), Adelaide, South Australia.

Rocha, J., Perdigo, A., Melo, R., Henriques, C., 2012. Remote Sensing Based Crop Coefficients for Water Management in Agriculture, Sustainable Development - Authoritative and Leading Edge Content for Environmental Management.

Sixsmith, J., Oliver, S., Lymburner, L., 2013. A hybrid approach to automated Landsat pixel quality, Geoscience and Remote Sensing Symposium (IGARSS). IEEE International, Melbourne, Australia, pp. 4146-4149.

Van Leeuwen, C., Tregoat, O., Choné, X., Bois, B., Pernet, D., Gaudillere, J.P., 2009. Vine Water Status is a Kay Factor in Grape Ripening and Vintage Quality for Red Bordeaux Wine. How Can it be Assessed for Vineyard Management Purposes? Journal Internaional des Sciences de la Vigne et du Vin 43, 121-134.

Vic Agriculture, 2012. Estimating vegetable crop water use. Victoria Agriculture Melbourne, Victoria, Australia.

WA DPIRD, 2016. Evaporation-based irrigation scheduling. Western Australia Department of Primary Industries and Regional Development, Perth, WA, Australia. 